\title{
SUSTAINABILITY VALUES OF STUDENTS AS INFLUENCES ON THE IMAGE OF A UNIVERSITY TRANSITIONING TO SUSTAINABILITY
}

\author{
ANNA A. MENDIOLA \\ Department of Marketing and Law, John Gokongwei School of Management \\ Ateneo de Manila University, Quezon City, Philippines \\ amendiola@ateneo.edu
}

\begin{abstract}
The journey toward sustainability is a difficult process for a university given the complex requirements necessary for becoming sustainable. To implement sustainability initiatives effectively, therefore, it is important to obtain the support and commitment of university stakeholders. Having a good image as far as the school's efforts at sustainability are concerned engages stakeholders and encourages that commitment. It is an important element of change as it provides evidence that the school is indeed serious in its activities. Yet is the perception of the school's image influenced by the sustainability values of students? A survey of 798 college students at a private university in Metro Manila, Philippines was conducted to establish the relationship of the students' sustainability values as these influenced their perception of the university's image. Structural equation modeling (SEM) with the EQS program was used to examine links between student sustainability values, perceptions of the impact of school initiatives, and school image. Results indicate that the school's image as a contributor to sustainability is influenced by the perception students have of the long-term impact of school initiatives and the importance they place on environmental management. Such results highlight the need for creating awareness about, as well as encouraging involvement with, sustainability initiatives among students, especially with activities that have long-term horizons. Creating such a positive image through the route established by this research would help provide focus and efficiencies in the university's sustainability initiatives.
\end{abstract}

\section{KEYWORDS}

sustainability; school image; SEM; environmental management 
The generally accepted definition of sustainability, which is a key topic in environmental discourse, is that of the World Commission on Environment and Development, where it is defined as the ability to "[meet] the needs of the present without compromising the ability of future generations to meet their own needs" (United Nations, 1987). To live sustainably, therefore, is about taking the needs of both the environment and future generations into account.

The 2005 World Summit on Social Development, on the other hand, describes development for sustainability as promoting the integration of three components, namely, environmental protection, economic development, and social development. These three aspects, seen to be "interdependent and mutually reinforcing pillars" for sustainable development (United Nations, 2005: 12) and often collectively referred to as the "triple bottom line," highlight the importance of recognizing social and economic issues that may negatively impact efforts at environmental protection. The move toward sustainable development is thus in keeping with the new environmental paradigm (NEP) that stresses how important it is to maintain the balance of nature and emphasizes that there are limits to resources, growth, and progress (Prothero et al., 2011).

The seriousness of environmental problems has also helped to increase awareness about sustainability and what it entails. This has led to a heightened interest in research, particularly with sustainability issues as an emerging field of inquiry. As such, given the urgency of environmental concerns, Prothero et al. (2011) suggest that research efforts must be concentrated and managed to maximize results. In particular, there are three possible research focus areas that have been identified as opportunities to be explored for increasing sustainable behavior. The first is at the individual level and relates to research on understanding why the positive attitudes of individuals toward sustainability are generally not accompanied by sustainable behavior. The second is at the micro level and focuses on the possible role that the consumer-citizen can play toward bridging this discrepancy. Finally, the third research area highlights the need for more knowledge on how the interventions of institutions and other organizations can help effect sustainable behavior.

Sustainability, when seen within the context of an institution and specifically within a university, is "the development of a process or management system that helps to create a vibrant campus economy and high quality of life while respecting 
the need to sustain natural resources and protect the environment" (Vanderbilt University, n.d.). It focuses primarily on the university's responsible management of resources that balances environmental concerns with societal and economic issues (NCSU, n.d.). Educational institutions as such are important contributors to raising awareness of sustainability issues as they can engage students in realistic and practical actions. Through education, research, and community involvement, universities can help produce societal change with long-lasting environmental effects (Ralph \& Stubbs, 2013) and promote the new environmental paradigm and its emphasis on maintaining the balance of nature (Prothero et al., 2011). UNESCO, too, has highlighted the importance of educational institutions as contributors to raising awareness of sustainability issues. Its vision is for everyone to have access to education that will teach the necessities for a future where the world is able to provide requirements for living without impacting negatively on the ability to meet subsequent needs (UNESCO, n.d.). The commitment to sustainability and achievement of the triple bottom line in universities can generally be seen, therefore, through the implementation of programs for sustainability.

Given the complex nature of sustainability, however, it is not easy for educational institutions to develop and implement campus initiatives on sustainable development. The process has often been described as slow and difficult (Rasmussen, 2011). Shriberg (2002) maintains that shifting to an orientation toward sustainable development entails a fundamental reorganization in terms of education, research, and interaction with stakeholders. Levy and Marans (2012) posit that both engagement and assessment aside from education are needed to encourage the development of pro-environment behavior among university stakeholders.

Yet despite the many obstacles in the journey toward sustainability, educational institutions have responded nevertheless to the call of the United Nations. Colleges and universities in many countries are increasingly evolving into models of environmental sustainability practices, thereby becoming catalysts of change in the process (Edwards, 2010, as cited by Rasmussen, 2011). There have also been a number of cases that illustrate the successful implementation of sustainable practices. In a study of three U.S. universities rated as environmentally-sustainable institutions, for instance, six factors were confirmed as having contributed to the achievement of campus sustainability; these are green campus operation measures; campus administration, organization, and leadership; teaching, research, and 
service; campus-wide actions and activities; institutional assessment of campus sustainability measures; and established methods for overcoming barriers (James \& Card, 2012).

In a study on a university that implemented a comprehensive environmental sustainability program, Rasmussen (2011) identified a number of strategies that can be pursued to support sustainability efforts. The most significant of these is implementing green practices such as programs for campus-wide recycling, renewable energy generation, and water conservation, among others. Another significant approach is in the area of education, through both a formal curriculum and co-curricular and extra-curricular activities that encourage critical thinking about environmental sustainability, while also providing support for research on the topic. Lastly, the importance of structural, human, and political support from campus stakeholders in facilitating the adoption of comprehensive sustainability initiatives was underscored as firm relationships with stakeholders were seen to be essential.

The involvement of stakeholders-students, faculty, and the community-is crucial as their consensus and buy-in are necessary for the success of sustainability initiatives on campus. They play an important role in supporting the implementation of sustainable practices (Stafford, 2011); indeed, sustainable environmental initiatives are most successful when university stakeholders coordinate their efforts and come together to create what Shriberg (2002) calls a "spark." Key components for success are the presence of collaborative decision-making structures, a progressive/ liberal political orientation, a collegial atmosphere, and image-seeking behavior (Shriberg, 2002). Elements of successful approaches to sustainability among institutions of higher education, in addition, are support from management, effective communication among stakeholders, partnerships with students, and the continuity of efforts (Sharp, 2002). From the other end of the spectrum, the lack of awareness of, and interest in, sustainability from stakeholders and support from administrators makes up some of the barriers to implementing sustainable practices on campus (Velazquez, Munguia, \& Sanchez, 2005). Lastly, it has been established that listening to stakeholders is important as environmental sustainability initiatives are unique to each institution and must therefore be evaluated on a case-to-case basis (Rasmussen, 2011). 
When it comes to students in particular as stakeholders, the youth of today are considered to be the future new leaders of the green movement. They have been brought up largely in an environmentally conscious society, and "green" is considered a part of their everyday life (Ottman, 2011). Perceived as the decisionmakers of tomorrow, they can significantly influence prospective sustainability efforts, thereby helping to ensure sustainable futures. Students in particular are thus seen as the most important drivers of environmental initiatives in an educational institution (Shriberg, 2002). However, while they do not appear to have a significant "knowledge gap" as regards campus sustainability, there seems to be a "commitment gap" which points to the necessity of getting them more involved with sustainability efforts (Emanuel \& Adams, 2011). Nevertheless, the importance of students as major stakeholders in schools indicates the imperative to listen to and understand them better as their support is critical to the success of a university's sustainability initiatives. This study, therefore, seeks to provide a deeper understanding of both the student as stakeholder and how their sustainability values influence the formation of their image of the university.

\section{THEORETICAL/CONCEPTUAL FRAMEWORK}

For this study, sustainability in education is framed in an expanded model for sustainability as depicted in Figure 1. This model illustrates the concept of sustainability in terms of the relationship of its three pillars, namely, social, economic, and environment, otherwise known as the triple bottom line. The key concept of sustainability is found at the intersection of the social, economic, and environmental aspects (Costa, Martins, \& Mata, 2006). Moreover, this expanded model also identifies the issues within the three spheres of sustainability as they relate to an educational institution (Rodriguez, Roman, Sturhahn, \& Terry, 2002). In the context of a university, the social aspect considers education, community, and standard of living; the economic aspect is measured by university profit as well as research and development efforts; and the environmental aspect is concerned with the environmental management of school resources, energy, water, and materials consumption, waste management, and pollution prevention. This model thus provides the lens through which students and university officials can evaluate sustainability initiatives and their impact on the school's image as a contributor to sustainability efforts. 


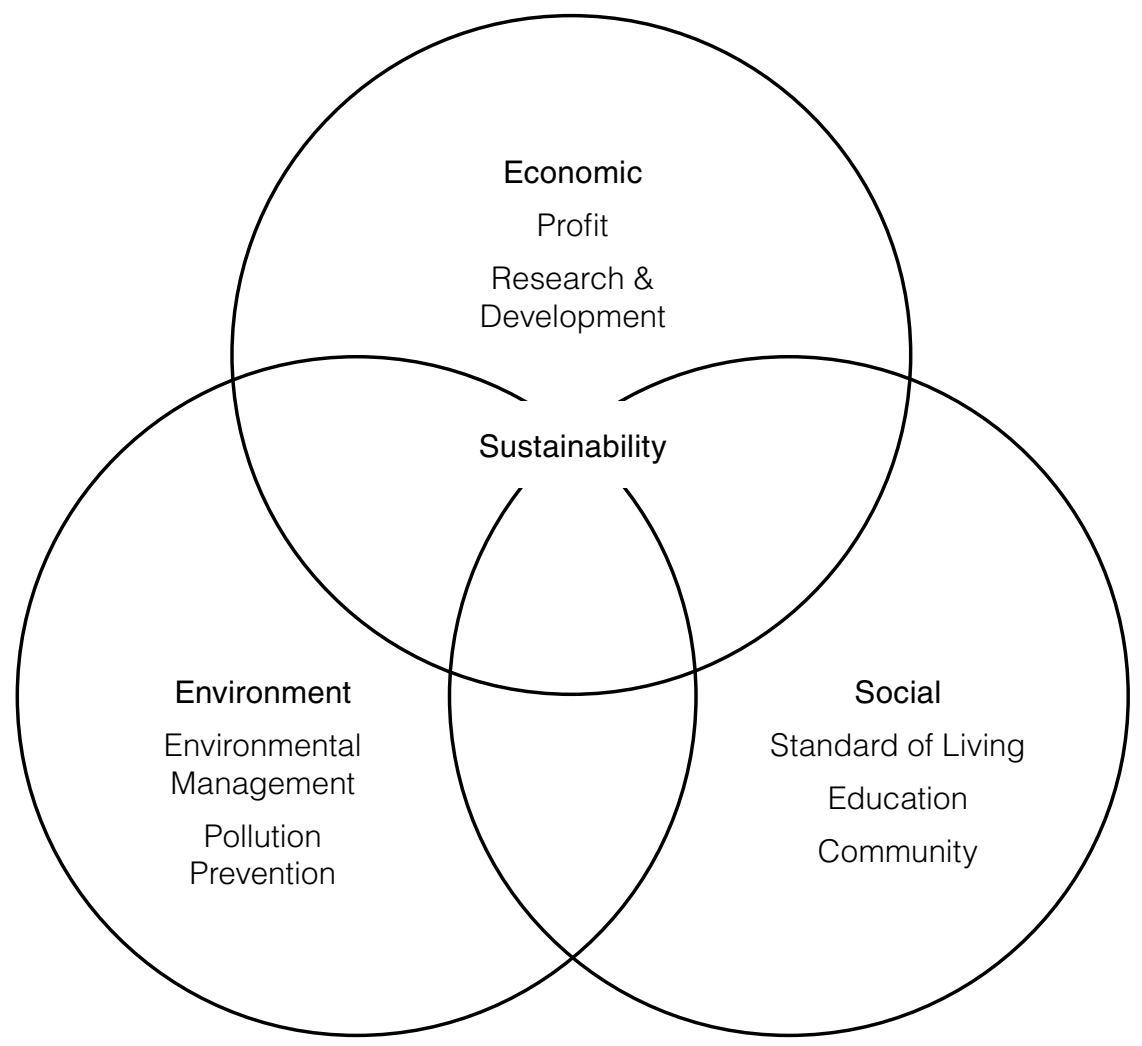

Figure 1: Issues Within the Three Spheres of Sustainability (adapted from Rodriguez et al., 2002: 8)

The importance of these three dimensions-social, economic, and environmental-to stakeholders must be determined to enable a better understanding of sustainability issues. They can be conceptualized as values associated with each aspect of sustainability. Here a value is defined as an "individual's concept of a transituational goal that expresses interests concerned with a motivational domain and evaluated on a range of importance as a guiding principle in (one's) life" (Schwartz \& Bilsky, 1987: 553). It concerns sentiments about how important something is to a person and is seen to have three basic attributes: its relativity, its subjectivity as it denotes a type of preference, and its role in personal decision-making (Carr, 1991). Values have also been established as important predictors of pro-environmental behavior as they influence involvement in sustainability activities (Schultz \& Zelezny, 1998). Theoretically, they can be 
located along a continuum ranging from "conservativism" to "openness to change" or from "egoism" to "altruism" (Sahin, Ertepinar, \& Teksoz, 2012). People who are more altruistic and open to change are also more likely to have a tendency toward pro-environmental behavior (Stern, Dietz, \& Guagnano, 1995). For this study, values are operationalized as social, economic, and environmental values of students specifically as they relate to an educational institution.

Social Values. Social values relate to the importance that students place in their academic performance and achievements, care and services provided to them by the school, and their general satisfaction as students of the university (Rodriguez et al., 2002). These values also include concerns about community building and engagement as well as the presence of formation and training programs for both the community and the students. They are related within a university context to the conditions that enhance the coordination and cooperation of stakeholders in activities that will serve to benefit all. The effective management of social issues thus contributes toward improving the organization's image, builds trust among stakeholders, and enhances the reputation of the school as a place where people would want to work or study in (Rodriguez et al., 2002).

Economic Values. Financial issues are considered a significant factor in the university's ability to adopt sustainable practices (Stafford, 2011). Economic values are thus related to how important the university's management of its material and financial resources is to students (Rodriguez et al., 2002). With revenues coming primarily from tuition fees, endowments and donations, research funding, and, for some institutions, government financial support, it is important that the university is able to manage these financial resources wisely and prudently so it can run its affairs effectively. Measures of the university's success in managing its financial resources can be seen in its financial performance and how it manages its investments, including those for endowments and donations (Rodriguez et al., 2002).

Environment Values. Environment values are related to the importance students place in the management and protection of campus ecology. This is associated with environmental issues inside a university setting, such as school utilities and material consumption and management, air emissions and water quality, and solid and wastewater management (Rodriguez et al., 2002). Such issues in general involve initiatives that provide for present and future ecologically focused activities and are oriented as well toward eliminating negative and harmful influences (Shriberg, 2002). 


\section{Perception of Long-Term Impact of School Initiatives}

It is instrumental to know if students perceive the school's initiatives to have long-term impact since they see these as the school's commitment to sustainability. Perception helps provide people with information about the characteristics of the things around them (Moganadas, Corral-Verdugo, \& Ramanathan, 2013). The perception that students have of the school's initiatives can thus influence the image they hold of the school when it comes to sustainability efforts. Indeed, systematic transformation requires long-term focus to institutionalize a universitywide commitment toward sustainability (Moganadas et al., 2013).

\section{Image of School as Contributing to Sustainability}

Image and reputation are key elements in effecting change (Shriberg, 2002). Symbolic commitment and the development of a "green" image are critical, especially as stakeholders demand evidence of the university's commitment to environmental sustainability (Rasmussen, 2011). Image-seeking behavior, too, has also been established as a key component in the success of a school's sustainability initiatives-institutions that work toward improving their image as it relates to sustainability are viewed as more likely to be receptive and encouraging toward sustainability initiatives (Shriberg, 2002). It is important, however, to ensure that the image is reflective of the actual values, vision, and strategy of the institution so that it does not fall into the trap of "green-washing," defined as "symbolic information emanating from within an organization without substantive actions" (Walker \& Wan, 2012: 231).

\section{STATEMENT OF THE PROBLEM}

Universities face many challenges in the transition toward sustainability. The literature, for one, has established how necessary it is to obtain the support and commitment of students for a school's sustainability initiatives to work. The importance that students place in sustainability may be measured by looking at their values as they relate to the social, economic, and environmental aspects of sustainability within the context of an educational institution. Yet do their sustainability values influence the way they see the school's efforts toward environmental sustainability? It is posited that students will have a more positive 
perception of their school's image the more developed their sustainability values are. Needless to say, then, it is important for the school to have a good image insofar as its efforts at sustainability are concerned because a good image engages students further and encourages their commitment to the school's efforts. However, the relationships between student sustainability values and the school's image within the context of sustainability are not very well understood, and there appears to be a gap in the literature as far as these are concerned.

This research thus provides a better understanding of the sustainability values of students as these relate to their perceived image of the university. The model it proposes seeks to establish that their social, economic, and environmental values influence their perceived image of the school as a contributor to sustainability efforts. Indeed, these values also seem to affect their perception of the longterm impact of university sustainability initiatives which is seen by students as representative of the school's commitment to sustainability. Such a perception, in turn, influences school image (Sharp, 2002). These relationships are depicted via a conceptual model as seen in Figure 2 .

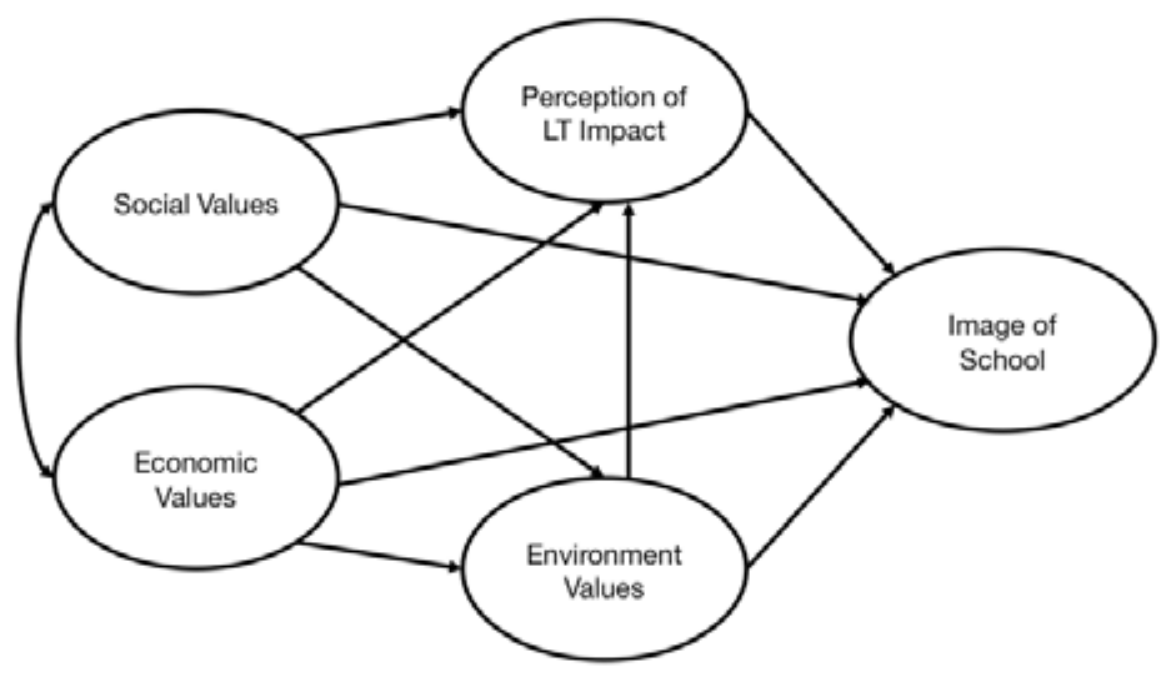

Figure 2: Conceptual Framework Showing the Proposed Relationship of Students' Social, Economic, and Environmental Values, Perception of Long-Term Impact of School Initiatives, and Image of School as Contributing to Sustainability 
The research questions for the purpose of this study are the following:

1. Do the students' social, economic, and environmental values influence their perceived image of the school as contributing to sustainability?

2. Do the students' social, economic, and environmental values influence their perception of the long-term impact of school initiatives?

3. Does the perception of the long-term impact of school initiatives influence their image of the school as contributing to sustainability?

The importance students place on social issues, including the long-term impact of school initiatives, will influence the way they view the school's management of those issues. Proper management of social issues enhances the school's image and builds trust in the school (Rodriguez et al., 2002). Indeed, the importance students place on community and student affairs is also hypothesized to have a relationship with the importance they give to the proper management and protection of the school environment, i.e., the more concerned they are about community and school affairs, the more likely they will appreciate that the school is run in an environmentally friendly manner.

As for economic and financial issues, these directly affect the school's ability to conduct sustainability initiatives (Stafford, 2011). Tackling environmental issues such as air emissions, water quality, etc. will certainly require a significant amount of school resources. Thus, if students find it important that the school is run in a financially responsible manner, this will have a direct influence on their image of the school as well as on its ability to implement sustainability initiatives for the long-term.

It is also proposed that there is a relationship between environmental values, which relate to the importance students place on the management and protection of the campus environment, and their image of the school as contributing to sustainability. Students will better be able to appreciate the school as contributing to sustainability the more developed their environmental values are. These values, in addition, are also hypothesized to influence the students' evaluation of the longterm impact of school initiatives. 
Finally, the recognition that transitioning to sustainability is a long, demanding, and arduous process for a university suggests that an appreciation of the longterm impact of school initiatives would lead to a positive image of the school as contributing to sustainability.

\section{METHOD}

The questionnaires used for this study were developed by a private university in Metro Manila and distributed to various sectors (faculty, students, and staff) and school units of the university through hard copies and by email.

Only the university student data was used for the purposes of this study. The survey was conducted on 798 university students across all college year and course levels. No other demographic data was required. Convenience sampling was implemented, with the questionnaires sent out to students through officers of student organizations and faculty members involved in the study. All efforts were exerted to ensure ethical treatment of respondents in the collection of data. The anonymity of respondents was strictly observed, and the confidentiality of data was maintained.

\section{Measures and Procedure}

All constructs were measured using university-designed statements. These were developed from several rounds of intensive consultations with various stakeholder groups, including university administrators, faculty, staff, and students. Most of the items were based on the Global Reporting Initiative framework (GRI, n.d.) while some were added based on the consultations with stakeholders.

Participants were asked to indicate their level of agreement with various statements to measure the importance of issues related to the various dimensions of sustainability. Each of these measures was rated on a 5-point Likert scale of 5Strongly Agree, 4-Agree, 3-Neutral, 2-Disagree, and 1-Strongly Disagree. They were also asked to indicate their level of agreement with statements regarding their perception of the school's initiatives. For their image of the school with reference to sustainability, participants were asked to rate each item on a 5-point Likert scale of 5-Strongly Agree, 4-Agree, 3-Neutral, 2-Disagree, and 1-Strongly Disagree. 
Social values were measured in terms of the importance of two distinct factors, namely, community formation and engagement, and student welfare. Participants were asked to indicate their level of agreement with whether or not specified community and student welfare values were important for them. These items were 1) community-building, 2) community engagement and feedback, 3) formation/training programs for students, 4) formation/training programs for employees, 5) student achievement/performance, 6) student care and services, and 7) student satisfaction.

Economic values were measured in terms of the importance of the school's financial performance and its management of financial resources. Respondents were asked to indicate their level of agreement with whether or not specified financial resources management aspects were important for them. These items were 1) financial performance and 2) investment risk management.

Environmental values were measured in terms of how important it is for students that the school properly handles the management of its environment, utilities, solid waste, and wastewater. Participants were asked to indicate their level of agreement as to which environmental values were important for them. These items were 1) utilities consumption and management (e.g., electricity, water, telecommunications), 2) environmental quality (e.g., water and air quality), 3) solid waste management and treatment, and 4) wastewater management and treatment.

Perception of the long-term impact of university initiatives was measured in terms of two distinct variables: first, in terms of its impact on student awareness and involvement, and, second, as regards the impact of initiatives on people and the community. These variables were measured in terms of the respondents' level of agreement with the following items:

1. I am aware of the school's plans and initiatives regarding disaster risk management (DRM);

2. I am involved in the environmental initiatives;

3. I am involved in the disaster risk management plans and initiatives;

4. The school invited me to participate in environment and development activities;

5. The school's environmental initiatives have long-term impact on the areas outside the school; and 
6. The school's environmental initiatives have long-term impact on people's habits.

Finally, there were three items related to having an image of the school as contributing to sustainability. These items were:

1. The (school) contributes to making our campus and operations more sustainable;

2. The (school) contributes to making our local community more sustainable; and

3. The (school) contributes to making our country more sustainable.

Factor analysis was conducted on all 22 items using Principal Axis Factor (PAF) analysis with an Oblimin (oblique) rotation. All the measures loaded cleanly to their respective factors with the exception of the social values factor and perception of school initiatives. Each of these latter two factors displayed two separate and distinct aspects. For the social values, four out of the original seven items loaded together, namely, 1) community-building, 2) community engagement and feedback, 3) formation/training programs for students, and 4) formation/training programs for employees; this emerging social factor was labeled Social Value(SV)-Community. The other three items that loaded together were 1) student achievement/performance, 2) student care and services, and 3) student satisfaction. This second emerging social factor was labeled Social Value(SV)-Student.

There were two distinct aspects for perception of school initiatives. The first factor describes school initiatives as it relates to the effect that these initiatives have on the student respondents. Loading together under this new factor were four items, namely,

1. I am aware of the school's plans and initiatives regarding disaster risk management (DRM);

2. I am involved in the environmental initiatives;

3. I am involved in the disaster risk management plans and initiatives; and

4. The school invited me to participate in environment and development activities.

This new factor was labeled Initiatives for Students. 
The second aspect for perception of school initiatives relates to the perception of the long-term impact of these initiatives on people and areas outside the school. Loading under this new factor are two items, namely,

1. The school's environmental initiatives have long-term impact on the areas outside the school, and

2. The school's environmental initiatives have long-term impact on people's habits.

This new factor was labeled Long-term Initiatives for Communities.

\section{Data Analysis}

Structural equation modeling (SEM) with the EQS programs (Bentler, ver. 6.2) was used to examine the links between student sustainability values, perceptions of the long-term impact of school initiatives, and school image. The exogenous variables were Social Value-Student, Social Value-Community, Initiatives for Students, and Economic Values. The endogenous variables were Long-term Initiatives for Communities, Environment Values, and Image of School as Contributing to Sustainability. Model specification analysis used was the default theory estimator Maximum Likelihood (ML) (Savalei \& Bentler, 2010) while the Robust method was utilized as data was not normally distributed.

The proposed model was evaluated based on identified dimensions. The first was goodness of fit to help determine if the proposed model was consistent with the data. Path estimates, correlations among exogenous variables, and R squared values for endogenous variables were also obtained.

To determine if the proposed model is a good approximation of reality, measures that provide evidence of good fit were used. These were the Satorra-Bentler scaled chi-square (Satorra \& Bentler, 2001), Comparative Fit Index (CFI; Bentler, 1990), and the Root Mean Square Error of Approximation (RMSEA; Browne \& Cudeck, 1993).

The Satorra-Bentler parameter is a scaled chi-square statistic that is commonly utilized as a benchmark and has particular applicability if the Robust method in SEM analysis is used. Good fit is indicated if the probability value is $\mathrm{p}>0.01$, as a non-significant relationship is a sign that the data and model are not significantly different from each other and that the model is therefore an adequate representation 
of the data (Satorra \& Bentler, 2001). It is important to note that chi-square values are influenced by sample size and the number of variables (Hair, Black, Babin, \& Anderson, 2010).

The Comparative Fit Index (CFI) assesses how well the model relates to a null model that assumes that all the variables are uncorrelated. A CFI Index that is $>.95$ would usually indicate that the model has a good fit while a CFI value of $>.90$ would be considered adequate (McDonald \& Ho, 2002).

The Root Mean Square Error of Approximation (RMSEA), on the other hand, indicates how well the model fits the population as it corrects for both complexity of the model and sample size (Hair et al., 2010). It is also considered to be best suited for confirmatory models with large sample sizes. McDonald and Ho (2002) consider an RMSEA value of $<.05$ as indicating good fit while a value of $<.08$ would be considered as adequate.

In running the SE model, the measurement model provided confirmatory factor analysis while the path analysis model illustrated the predicted factor and the factor predictors per endogenous variable. The exogenous variables were also tested for correlations among the various predictors.

\section{RESULTS}

The factor analysis performed on all 22 variables showed a seven-factor solution with a total variance explained of $62.6 \%$, indicating that the results substantially explain the total variance. Reliability scores for the seven factors were high as seen in the Cronbach's alpha value for each factor. These were .83 for Social Value-Student, .86 for Initiatives for Students, .77 for Social Value-Community, .85 for Economic Values, .85 for Long-term Initiatives for Communities, .81 for Environment Values, and .81 for Image of School as Contributing to Sustainability, respectively. Details on factor loadings and reliability scores are shown in Appendix A. Mean scores for indicators range from 3.95 to 5.71 with all indicators negatively skewed except for one. Descriptive statistics for the factor indicators are shown in Appendix B.

The hypothesized structural equation model shown in Figure 3 was tested through SEM analysis to explain the relationships among the factors. The output of the analysis indicated that the problem was "solvable." Running the model showed 
that there were no problems with the model estimation as the parameter estimates were seen to be in order.

Goodness-of-fit tests showed the RMSEA with a value of $.06<.08$, pointing to a relatively good fit of the model to the data. The CFI showed good fit likewise at .92 . The Satorra-Bentler scaled chi-square, however, was significant at $\chi^{2}(197, \mathrm{~N}=798)=$ $613.75, \mathrm{p}<.01$, indicating that the model does not quite fit the data. Nevertheless, such results generally point to the acceptability of the model, with two out of three measures of goodness of fit indicating that the model adequately represents the data. It has been established, moreover, that the chi-square is sensitive to sample size and tends to be significant if the sample size is large (McDonald \& Ho, 2002). This may be assumed as the case for this model. The resulting SE model is shown in Figure 3, with more details provided in Table C1.

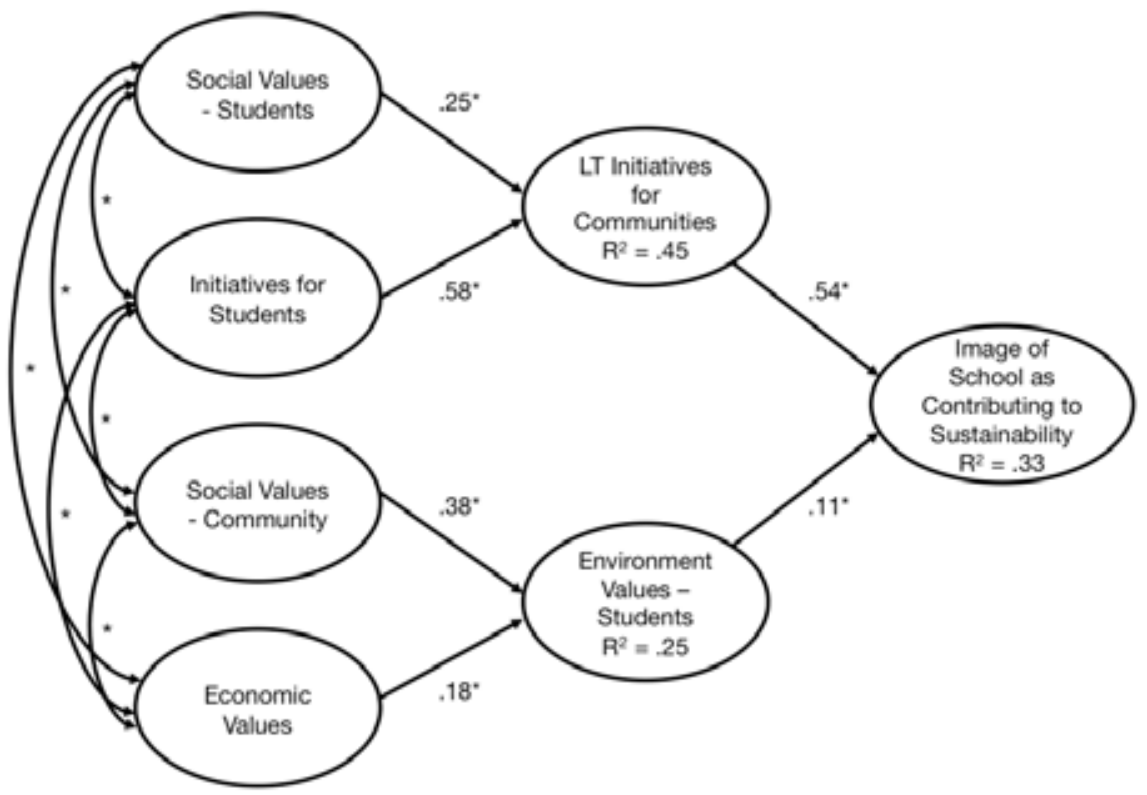

Figure 3: Structural Equation Model Showing the Standardized Path Estimates of Social Values-Students, Initiatives for Students, Social Values-Community, Economic Values, Long Term Initiatives for Communities, Environment Values, and Image of School as Contributing to Sustainability ( ${ }^{*}$ significant values) 


\begin{tabular}{|c|c|c|}
\hline VARIABLES & $\begin{array}{l}\text { STANDARDIZED } \\
\text { SOLUTION }\end{array}$ & $\begin{array}{c}\text { R- } \\
\text { SQUARED }\end{array}$ \\
\hline \multicolumn{3}{|l|}{ Image of School = F1 } \\
\hline Contribution to Campus $=\mathrm{V} 4$ & $\mathrm{~V} 4=.68 \mathrm{~F} 1+.73 \mathrm{E} 4$ & 0.46 \\
\hline Contribution to Community =V5 & $\mathrm{V} 5=.86^{\star} \mathrm{F} 1+.51 \mathrm{E} 5$ & 0.74 \\
\hline Contribution to Country =V 6 & $\mathrm{~V} 6=.81^{\star} \mathrm{F} 1+.59 \mathrm{E} 6$ & 0.65 \\
\hline \multicolumn{3}{|l|}{ Social Values - Community = F2 } \\
\hline Community Building $=\vee 7$ & $\mathrm{~V} 7=.74 \mathrm{~F} 2+.67 \mathrm{E} 7$ & 0.55 \\
\hline Community Engage =V8 & $\mathrm{V} 8=.71^{\star} \mathrm{F} 2+.71 \mathrm{E} 8$ & 0.50 \\
\hline Formation Student $=\mathrm{V} 9$ & $\mathrm{~V} 9=.68^{*} \mathrm{~F} 2+.73 \mathrm{E} 9$ & 0.46 \\
\hline Formation Employee $=\mathrm{V} 10$ & $\mathrm{~V} 10=.65^{\star} \mathrm{F} 2+.76 \mathrm{E} 10$ & 0.42 \\
\hline \multicolumn{3}{|l|}{ Social Values - Student $=$ F3 } \\
\hline Student Achievement $=\mathrm{V} 11$ & $\mathrm{~V} 11=.76 \mathrm{~F} 3+.64 \mathrm{E} 11$ & 0.58 \\
\hline Student Care $=\mathrm{V} 12$ & $\mathrm{~V} 12=.84^{\star} \mathrm{F} 3+.54 \mathrm{E} 12$ & 0.71 \\
\hline Student Satisfaction $=$ V13 & $\mathrm{V} 13=.77^{\star} \mathrm{F} 3+.64 \mathrm{E} 13$ & 0.59 \\
\hline \multicolumn{3}{|l|}{ Environment Values = F4 } \\
\hline Utilities Consumption =V14 & $\mathrm{V} 14=.49 \mathrm{~F} 4+.87 \mathrm{E} 14$ & 0.24 \\
\hline Environmental Quality =V15 & $\mathrm{V} 15=.51^{\star} \mathrm{F} 4+.86 \mathrm{E} 15$ & 0.26 \\
\hline Solid Waste Mgmt =V16 & $\mathrm{V} 16=.92^{*} \mathrm{~F} 4+.40 \mathrm{E} 16$ & 0.84 \\
\hline Wastewater Mgmt =V17 & $\mathrm{V} 17=.90 * \mathrm{~F} 4+.44 \mathrm{E} 17$ & 0.81 \\
\hline \multicolumn{3}{|l|}{ Economic Values $=$ F5 } \\
\hline Financial Performance $=$ V18 & $\mathrm{V} 18=.87 \mathrm{~F} 5+.49 \mathrm{E} 18$ & 0.76 \\
\hline Investment Risk Mgmt =V19 & $\mathrm{V} 19=.87^{\star} \mathrm{F} 5+.50 \mathrm{E} 19$ & 0.75 \\
\hline \multicolumn{3}{|l|}{ Initiatives for Students = F6 } \\
\hline I am Aware of Plans =V20 & $\mathrm{V} 20=.70 \mathrm{~F} 6+.71 \mathrm{E} 20$ & 0.49 \\
\hline I am Involved in Initiatives =V21 & $\mathrm{V} 21=.79^{\star} \mathrm{F} 6+.61 \mathrm{E} 21$ & 0.62 \\
\hline I am Involved in DRM Plans =V22 & $\mathrm{V} 22=.88^{*} \mathrm{~F} 6+.47 \mathrm{E} 22$ & 0.78 \\
\hline School Invited Me =V23 & $\mathrm{V} 23=.74^{\star} \mathrm{F} 6+.67 \mathrm{E} 23$ & 0.55 \\
\hline \multicolumn{3}{|l|}{ LT Initiatives for Communities = F7 } \\
\hline LT Impact Outside =V24 & $\mathrm{V} 24=.90 \mathrm{~F} 7+.43 \mathrm{E} 24$ & 0.82 \\
\hline LT Impact on People =V25 & $.83^{\star} \mathrm{F} 7+.55 \mathrm{E} 25$ & 0.69 \\
\hline Image of School = F1 & $\mathrm{F} 1=.11^{\star} \mathrm{F} 4+.54^{\star} \mathrm{F} 7+.82 \mathrm{D} 1$ & 0.33 \\
\hline Environment Values $=\mathrm{F} 4$ & $\mathrm{~F} 4=.38^{\star} \mathrm{F} 2+.18^{*} \mathrm{~F} 5+.87 \mathrm{D} 4$ & 0.25 \\
\hline LT Initiatives for Communities = F7 & $\mathrm{F} 7=.25^{\star} \mathrm{F} 3+.58^{\star} \mathrm{F} 6+.74 \mathrm{D} 7$ & 0.45 \\
\hline
\end{tabular}

Table C1: Standardized Path Estimates of Social Values-Student, Initiatives for Students, Social Values-Community, Economic Values, Environment Values, LT Initiatives for Communities, and School's Image as Contributing to Sustainability 
The measurement model showed all the relationships of the items with their respective factors as significant. Results also showed significant correlations among all exogenous factors. The structural model, on the other hand, illustrated that perception of Long-term Initiatives for Communities and Environment Values were significant predictors of Image of School as Contributing to Sustainability. These two factors accounted for 33\% of the variance for the school's image. In addition, Social Value-Student and Initiatives for Students were significant predictors of Long-term Initiatives for Communities, together accounting for $45 \%$ of its variance. Lastly, Economic Values and Social Value-Community significantly predicted Environment Values, contributing $25 \%$ of the variance for the latter.

As seen in Table C1, perception of Long-term Initiatives for Communities was the most important predictor of Image of School as Contributing to Sustainability with a path coefficient of .54 . It has a strong, positive relationship with the latter. This means that the more students see that the school's long-term initiatives are for communities, the more they will think that the school contributes to sustainability. Likewise, Environment Values significantly predicted Image of School as Contributing to Sustainability, albeit on a less important level, with a path coefficient of .11. It has a weak positive relationship with Image. This means that the more students see the environmental management of utilities consumption and of air/water quality, as well as solid waste/wastewater management and treatment, as important, the more highly they think of the school in terms of contributing to sustainability.

The more important predictor for the perception of Long-term Initiatives for Communities is Initiatives for Students with a path coefficient of .58. Both factors have a strong, positive relationship with each other. If the school's sustainability activities enjoy high student awareness and involvement, the students better appreciate long-term initiatives done for communities. Social Values-Students is likewise a significant predictor of perception of Long-term Initiatives for Communities with a path coefficient of .25 . The relationship is positive yet somewhat weak. Nevertheless, if students value their achievements highly and see it as important that they are taken care of by the school, then they would better appreciate the long-term impact of the school's initiatives for communities.

For Environment Values, the more significant predictor is Social ValueCommunity with a path coefficient of .38. This indicates a moderate, positive 
relationship. If students value community building and engagement and find formation/training programs for both students and employees to be important, they will also value the environmental management of utilities and air/water quality as well as the handling of solid waste/wastewater effluences. Economic Values also significantly predict Environment Values with a path coefficient of .18. The relationship is positive though weak. It signifies that students who find it important that the school manages its financial resources properly will also better appreciate the management of environmental resources.

In summary, the results of the SEM analysis confirm that a school's image as a contributor to sustainability efforts is significantly influenced by students' appreciation of the long-term impact of the school's sustainability initiatives for communities and by the importance they put on environmental management. The students in turn value the long-term impact of the school's initiatives for communities if they have high awareness of and involvement in sustainability activities and if they put great importance on student welfare. Environment values, on the other hand, are predicted by how students feel about community engagement and formation and the school's handling of financial resources.

\section{DISCUSSION}

It is inevitable that many challenges and hurdles will need to be overcome for a university transitioning toward sustainability. To be successful in its efforts, the need to engage stakeholders is clear (Levy \& Marans, 2012; Rasmussen, 2011; Shriberg, 2002; Sharp, 2002). This research accordingly provides insights on the sustainability values of students and how these impact on the image of a university transitioning toward sustainability. Sustainability values indicate how important social, economic, and environment issues are for students. Moreover, the strategic importance of building a good image as far as sustainability issues are concerned has also been pointed out consistently in the literature (Shriberg, 2002; Rasmussen, 2011, Sahin et al., 2012). Image and image-seeking behavior represent some of the strong positive conditions for success in sustainability initiatives which are most fruitful when driven by various stakeholders, including students (Shriberg, 2002).

This research focuses on school image as it is an important element in transitioning toward sustainability. The findings show that the image of the 
school as contributing to sustainability is influenced primarily by the perception that the school is doing long-term initiatives for communities. The greater the perception, the more positive the school's image will be. The environment values of students also contribute as well to the image of the school, indicating that the more students find the environment important, the more likely they will see the school as contributing to sustainability.

These results, therefore, propose an efficient route toward achieving a good image of the school as a contributor to sustainability. Since the perception that long-term initiatives are being done for communities is predictive of a good image, the school may more effectively achieve favorable representation if it focuses on community activities that have long-term impact on sustainability. It is crucial, furthermore, that these sustainability initiatives consider the environmental issues that students find important. Thus, given the many activities that can be done in the name of sustainability, this indicates that the university must focus prudently on those that provide long-term benefits instead of short-term gains. The scale of efforts, therefore, must be wider, more ambitious, and have greater influence. Such efforts, needless to say, will have a significant impression on students if they are implemented campus-wide, well-coordinated, and well-publicized.

The more significant predictor of the perception that the school has longterm initiatives for communities are the initiatives for students that describe their level of awareness of and involvement in environmental activities. Indeed, what the students find important in their lives as students, namely, their achievement and performance, student care and services, and student satisfaction, predict this perception of the school as well. Thus, for students to appreciate the long-term impact of these initiatives, the school must be cognizant of the fact that it needs to engage students and ensure the facilitation of awareness about, and participation in, environmental activities. The challenge may be in developing sustainability projects that maximize student involvement and solicit their support in the process. It appears, moreover, that students also need to think that the school is taking care of their needs well before they can fully appreciate any environmental initiatives.

Lastly, the findings related to environment values imply that university efforts should focus on community formation and engagement activities as these contribute to a better appreciation of environmental issues and appear to make 
students better appreciate sustainability issues as they impact the community. This suggests, then, that there is a need for the university to provide venues and opportunities for the students and the community to come together and work toward common environmental goals. Students, moreover, also think that sound financial management will better enable the school to handle environmental issues which they find to be important.

Having a good image as a contributor to sustainability, then, is a necessary element in the success of a school's sustainability initiatives, especially given that stakeholders require evidence of the university's commitment to environmental sustainability (Rasmussen, 2011). A good image is an important element of change as it is considered to provide the evidence needed by students to show that the school is indeed serious in its efforts at sustainability (Shriberg, 2002). Sahin et al. (2012) established that people who find sustainability issues important are more likely "to engage more actively with the social, environmental, and economic aspects of sustainable development" (472). Engaging students in efforts toward sustainability, therefore, requires a coordinated effort in the marketing of the school's initiatives.

Creating that positive image through the route established by this study would thus help provide focus and efficiencies in terms of a school's sustainability initiatives. Indeed, this research points out the need to do the following in developing a good image of the school as one transitioning to sustainability:

1. focus on sustainability initiatives that provide long-term benefits to help communities and contribute to community formation;

2. engage students in these community sustainability activities by creating awareness of, and providing avenues for participation in, these environmental projects while being supportive of their needs; and

3. ensure that effective management practices are in place that make prudent use of resources as financial issues clearly affect the university's ability to create and adopt sustainable practices.

Educational institutions play a vital role indeed in raising awareness about sustainability issues since they can engage students in realistic and feasible actions (Ralph \& Stubbs, 2013). A lack of awareness of sustainability initiatives, meanwhile, is seen as a significant barrier to the implementation of sustainable 
practices (Velazquez et al., 2005). Information on sustainability values, moreover, could be particularly useful in the development of more proactive and effective efforts aimed at educating the youth on, and engaging them in, sustainability and pro-environment activities. Finally, the results of this study could also be used in the development of interventions that could have a strong influence on the sustainability values of students, thereby increasing their engagement and helping generate support for a school transitioning to sustainability.

\section{LIMITATIONS OF THIS STUDY AND RECOMMENDATIONS FOR FUTURE RESEARCH}

This study has a number of limitations. For one, it covers only university students who come from a private educational institution that caters mostly to the upper socio-economic classes. Bigger and wealthier institutions are more likely to move toward becoming sustainable vis-à-vis smaller, less wealthy organizations (Stafford, 2011). The results, therefore, may not be generalizable as they can differ greatly if the research involved students from public or less well-endowed schools. Moreover, as the university is located in a highly urbanized area, there may be significant differences in results if the research was conducted in a rural or less urbanized setting where sustainability issues may not be as pressing.

Future studies could focus on other stakeholders of the university such as faculty, staff, and alumni. Research efforts to determine which marketing and community activities would best elicit desired student involvement could also be conducted. Such efforts would certainly lead to a more comprehensive understanding of sustainability issues within a university and, as a consequence, a more cohesive and possibly less bumpy approach in transitioning toward sustainability.

\section{REFERENCES}

Bentler, P. M. 1990. Comparative fit indexes in structural models. Psychological Bulletin, 107(2): 238-246.

Browne, M. W., \& Cudeck, R. 1993. Alternative ways of assessing model fit. In K. Bollen \& J. Long (Eds.), Testing structural equation models: 136-162. Newbury Park, CA: Sage. 
Carr, D. 1991. Education and values. British Journal of Educational Studies, 39(3): 244-259.

Costa, C. A., Martins, A. A., \& Mata, T. M. 2006. Education for sustainability: Challenges and trends. Clean Technologies and Environmental Policy, 8(1): 31-37.

Emanuel, R., \& Adams, J. N. 2011. College students' perceptions of campus sustainability. International Journal of Sustainability in Higher Education, 12(1): 79-92.

GRI [Global Reporting Initiative]. n.d. About GRI. Available at https://www. globalreporting.org/Information/about-gri/Pages/default.aspx.

Hair, J. F., Black, W. C., Babin, B. J., \& Anderson, R. E. 2010. Multivariate data analysis. Upper Saddle River, NJ: Pearson Prentice Hall.

James, M., \& Card, K. 2012. Factors contributing to institutions achieving environmental sustainability. International Journal of Sustainability in Higher Education, 13(2): 166-176.

Levy, B. M., \& Marans, R. W. 2012. Towards a campus culture of environmental sustainability: Recommendations for a large university. International Journal of Sustainability in Higher Education, 13(4): 365-377.

McDonald, R. P., \& Ho, M.-H. R. 2002. Principles and practice in reporting structural equation analyses. Psychological Methods, 7(1): 64-82.

Moganadas, S. R., Corral-Verdugo, V., \& Ramanathan, S. 2013. Toward systemic campus sustainability: Gauging dimensions of sustainable development via a motivational and perception-based approach. Environment, Development, and Sustainability, 15(6): 1443-1464.

NCSU [North Carolina State University]. n.d. Why sustainability? Available at http:// sustainability.ncsu.edu/about/what-is-sustainability.

Ottman, J. A. 2011. The new rules of green marketing. San Francisco: BerrettKoehler Publishers. 
Prothero, A., Dobscha, S., Freund, J., Kilbourne, W. E., Luchs, M. G., Ozanne, L. K., \& Thøgersen, J. 2011. Sustainable consumption: Opportunities for consumer research and public policy. Journal of Public Policy \& Marketing, 30(1): 31-38.

Ralph, M., \& Stubbs, W. 2013. Integrating environmental sustainability into universities. Higher Education, 67(1): 71-90.

Rasmussen, J. E. 2011. Transitioning to green: Implementing a comprehensive environmental sustainability initiative on a university campus. Doctoral dissertation, California State University, Long Beach, CA. Available at ProQuest Dissertations and Theses Database (UMI No. 3485376).

Rodriguez, S. I., Roman, M. S., Sturhahn, S. C., \& Terry, E. H. 2002. Sustainability assessment and reporting for the University of Michigan's Ann Arbor campus. Center for Sustainable Systems Report No. CSSO2-04. Ann Arbor, MI: University of Michigan.

Sahin, E., Ertepinar, H., \& Teksoz, G. 2012. University students' behaviors pertaining to sustainability: A structural equation model with sustainability-related attributes. International Journal of Environmental and Science Education, 7(3): 459-478.

Satorra, A., \& Bentler, P. M. 2001. A scaled difference chi-square test statistic for moment structure analysis. Psychometrika, 66(4): 507-514.

Savalei, V., \& Bentler, P. M. 2010. Structural equation modeling. In I. B. Weiner \& W. E. Craighead (Eds.), The Corsini encyclopedia of psychology: 1-3. Hoboken, NJ: John Wiley.

Schultz, P. W., \& Zelezny, L. C. 1998. Values and proenvironmental behavior: A five-country survey. Journal of Cross-Cultural Psychology, 29(4): 540-558.

Schwartz, S. H., \& Bilsky, W. 1987. Toward a universal psychological structure of human values. Journal of Personality and Social Psychology, 53(3): 550-562.

Sharp, L. 2002. Green campuses: The road from little victories to systematic transformation. International Journal of Sustainability in Higher Education, 3(2): 128-145. 
Shriberg, M. 2002. Sustainability in United States higher education: Organizational factors influencing campus environmental performance and leadership. Doctoral dissertation, University of Michigan, Michigan.

Stafford, S. L. 2011. How green is your campus? An analysis of the factors that drive universities to embrace sustainability. Contemporary Economic Policy, 29(3): 337-356.

Stern, P. C., Dietz, T., \& Guagnano, G. A. 1995. The new ecological paradigm in social-psychological context. Environment and Behavior, 27(6): 723-743.

UNESCO [United Nations Educational, Scientific, and Cultural Organization]. n.d. Education for sustainable development. Available at https:/en.unesco.org/ themes/education-sustainable-development.

United Nations. 1987. Report of the World Commission on Environment and Development: Our common future. Available at http://www.un-documents. net/our-common-future.pdf.

United Nations. 2005. 2005 world summit outcome. Available at https://www. ilo.org/wcmsp5/groups/public/---dgreports/---integration/documents/ meetingdocument/wcms_079439.pdf.

Vanderbilt University. n.d. What is sustainability? Available at http://www. vanderbilt.edu/sustainvu/who-we-are/what-is-sustainability/.

Velazquez, L., Munguia, N., \& Sanchez, M. 2005. Deterring sustainability in higher education institutions: An appraisal of the factors which influence sustainability in higher education institutions. International Journal of Sustainability in Higher Education, 6(4): 383-391.

Walker, K., \& Wan, F. 2012. The harm of symbolic actions and green-washing: Corporate actions and communications on environmental performance and their financial implications. Journal of Business Ethics, 109(2): 227-242. 


\section{APPENDICES}

\begin{tabular}{|l|c|c|c|c|c|c|c|c|}
\hline & $\mathrm{A}$ & $\mathrm{B}$ & $\mathrm{C}$ & $\mathrm{D}$ & $\mathrm{E}$ & $\mathrm{F}$ & $\mathrm{G}$ & $\mathrm{R}^{2}$ \\
\hline Student Care \& Services & & & & & & & & \\
Student Satisfaction & .78 & & & & & & & .71 \\
Student Achievement/ & .75 & & & & & & & .59 \\
Performance & .72 & & & & & & & .58 \\
I am Involved in DRM Plans & & & & & & & & \\
I am Involved in Initiatives & & -.95 & & & & & & .78 \\
The School Invited Me & & -.67 & & & & & & .62 \\
I am Aware of Plans & & -.63 & & & & & & .55 \\
Solid Waste Management & & & .95 & & & & & .89 \\
Wastewater Management & & & .86 & & & & & .81 \\
Environmental Quality & & & .45 & & & & & .26 \\
Utilities Consumption and & & & .42 & & & & & .24 \\
Management & & & & & & & & \\
Contribution to Community & & & & .89 & & & & .74 \\
Contribution to Country & & & & .82 & & & & .65 \\
Contribution to Campus & & & & .64 & & & & .46 \\
Community Building & & & & & -.80 & & & .55 \\
Community Engagement & & & & & -.79 & & & .50 \\
Formation Students & & & & & -.44 & & & .46 \\
Formation Employees & & & & & -.42 & & & .42 \\
Investment Risk Mgmt & & & & & & -.86 & & .75 \\
Financial Performance & & & & & & -.77 & & .76 \\
Long-term Impact Outside & & & & & & & -.78 & .82 \\
Long-term Impact People & & & & & & & -.69 & .69 \\
& & & & & & & & \\
\hline Cronbach's Alpha & & & & & & & \\
\hline
\end{tabular}

Appendix A: Construct Validity and Reliability of Measures*

*Sustainability Factors, Principal Axis Factoring, Oblimin with Kaiser Normalization Rotation, Pattern Matrix for 22 Sustainability Items ( $N=798)$. Factor loadings $<.40$ are suppressed. LEGEND: A-SV Student; B-Initiatives for Students; C-Environment; D-School Image; E-SV Community; F-Economic Values; G-Initiatives for Communities. 


\begin{tabular}{|c|c|c|c|c|}
\hline & M & SD & Skewness & Kurtosis \\
\hline \multicolumn{5}{|l|}{ Social Values - Students } \\
\hline Student Care \& Services & 5.63 & .56 & -1.35 & 1.54 \\
\hline Student Satisfaction & 5.59 & .59 & -1.43 & 2.70 \\
\hline Student Achievement/ & 5.54 & .64 & -1.31 & 1.53 \\
\hline Performance & & & & \\
\hline \multicolumn{5}{|l|}{ Initiatives for Students } \\
\hline I am Involved in DRM Plans & 4.10 & .97 & .14 & -.32 \\
\hline I am Involved in Initiatives & 4.36 & .99 & -.12 & -.50 \\
\hline The School Invited Me & 4.31 & 1.05 & -.16 & -.64 \\
\hline I am Aware of Plans & 4.47 & .96 & -.25 & -.58 \\
\hline \multicolumn{5}{|l|}{ Environment Values } \\
\hline Solid Waste Management & 5.52 & .60 & -.92 & .023 \\
\hline Wastewater Management & 5.51 & .61 & -.94 & .21 \\
\hline Environmental Quality & 5.71 & .51 & -1.58 & 1.94 \\
\hline Utilities Consumption and & 5.44 & .67 & -.87 & -.04 \\
\hline Management & & & & \\
\hline \multicolumn{5}{|l|}{ Image of School's Contribution } \\
\hline Contribution to Community & 4.05 & .76 & -.54 & .16 \\
\hline Contribution to Country & 3.95 & .78 & -.54 & .41 \\
\hline Contribution to Campus & 4.32 & .68 & -.87 & 1.00 \\
\hline \multicolumn{5}{|l|}{ Social Values - Community } \\
\hline Community Building & 5.24 & .70 & -.57 & .02 \\
\hline Community Engagement & 5.19 & .69 & -.43 & -.12 \\
\hline Formation Students & 5.50 & .65 & -1.16 & 1.00 \\
\hline Formation Employees & 5.32 & .74 & -.73 & -.30 \\
\hline \multicolumn{5}{|l|}{ Economic Values } \\
\hline Investment Risk Mgmt & 5.26 & .72 & -.58 & -.44 \\
\hline Financial Performance & 5.28 & .74 & -.65 & -.34 \\
\hline \multicolumn{5}{|l|}{ LT Initiatives for Communities } \\
\hline Long-term Impact Outside & 4.80 & .82 & -.38 & .21 \\
\hline Long-term Impact People & 4.83 & .89 & -.46 & .02 \\
\hline
\end{tabular}

Appendix B: Descriptive Statistics (for Means, Skewness, and Kurtosis for each Factor Variable $[\mathrm{N}=798])$

Anna A. Mendiola is an Assistant Professor with a Masters in Business Administration from the University of the Philippines and a Ph.D. in social-organizational psychology from the Ateneo de Manila University where she teaches mostly marketing subjects such as Principles of Marketing, Brand Management, and Consumer Behavior and Marketing Psychology at the John Gokongwei School of Management. She has had extensive experience in the field of marketing prior to joining Ateneo, having spent more than 15 years handling various FMCG categories at Kimberly-Clark Philippines. 